University of Nebraska - Lincoln

DigitalCommons@University of Nebraska - Lincoln

2009

\title{
The Genus Arnoldiola (Diptera: Cecidomyiidae) in the Nearctic Region, with New Synonymies and Combinations
}

\author{
Raymond Gagne \\ Systematic Entomology Laboratory, PSI, Agricultural Research Service, USDA, c/o U. S. National Museum \\ NHB 168, P.O. Box 37012, Washington, DC 20013-7012, USA, raymond.gagne@ars.usda.gov
}

Follow this and additional works at: https://digitalcommons.unl.edu/systentomologyusda

Part of the Entomology Commons

Gagne, Raymond, "The Genus Arnoldiola (Diptera: Cecidomyiidae) in the Nearctic Region, with New Synonymies and Combinations" (2009). USDA Systematic Entomology Laboratory. 23.

https://digitalcommons.unl.edu/systentomologyusda/23

This Article is brought to you for free and open access by the Entomology Collections, Miscellaneous at DigitalCommons@University of Nebraska - Lincoln. It has been accepted for inclusion in USDA Systematic Entomology Laboratory by an authorized administrator of DigitalCommons@University of Nebraska - Lincoln. 


\title{
THE GENUS ARNOLDIOLA (DIPTERA: CECIDOMYIIDAE) IN THE NEARCTIC REGION, WITH NEW SYNONYMIES AND COMBINATIONS
}

\author{
RAYMOnd J. GAGnÉ
}

Systematic Entomology Laboratory, PSI, Agricultural Research Service, U.S. Department of Agriculture, c/o National Museum of Natural History, Smithsonian Institution, P.O. Box 37012, MRC 168, Washington, DC 20013-7012, U.S.A. (e-mail: Raymond.Gagne@ars.usda.gov)

Abstract. - Six nominal species of gall midges (Diptera: Cecidomyiidae) originally assigned to four separate genera and recognized here as three valid species are transferred to Arnoldiola Strand. They are as follows: Arnoldiola azaleae (Felt 1907a), new combination (from Oligotrophus Latreille); Arnoldiola caudata (Felt 1915), new combination (from Phytophaga Rondani) and new synonym of A. azaleae; Arnoldiola brevicornis (Felt 1907a), new combination (from Janetiella Kieffer); Arnoldiola tiliacei (Felt 1907a), new combination (from Janetiella) and new synonym of A brevicornis; Arnoldiola castaneae (Felt 1909), new combination (from Rhopalomyia Rübsaamen); and Arnoldiola ligni (Felt 1915), new combination (from Janetiella) and new synonym of A. castaneae. Diagnostic characters of the genus are outlined, and the newly combined species are described with some characters illustrated.

Key Words: gall midges, Holarctic, oak, chestnut

Arnoldiola Strand has long been known from oaks in the Palearctic Region but was only recently noted in the Nearctic Region by Gagné and Riley (1999) with the discovery of Arnoldiola atra Gagné on live oak in Texas. The suggestion was made in that article that $A$. atra was a new introduction into the United States because its serious and widespread damage to oak buds in Texas had never previously been remarked upon. While constructing a key to genera of Cecidomyiidae in the Nearctic Region, I found six previously described species that also belong in Arnoldiola. Three were in Janetiella Kieffer, and the other three were "Unplaced Cecidomyiinae" of Gagné (2004). All were named by Felt and originally variously placed in

\footnotetext{
* Accepted by David R. Smith
}

four separate genera. Only one of them, Rhopalomyia castaneae Felt, had been reared from definite plant damage. Their presence in North America and the fact that one was reared from Castanea dentata (Marsh.) Borkh. (Fagaceae) indicates that the genus is native across much of the Holarctic, and its host range includes chestnut as well as oak. Arnoldiola otherwise comprises 11 Palearctic species. Seven of those 11, including the type species, Arnoldiola quercus Binnie from Europe, are associated with galls on oak (Gagné 2004). I do not know whether those not connected with Fagaceae properly belong in the genus.

Arnoldiola was previously distinguished from other Dasineurini by the foreshortened antennal flagellomeres in both sexes (Figs. 1-3). Another consistent character noticed here, on all 

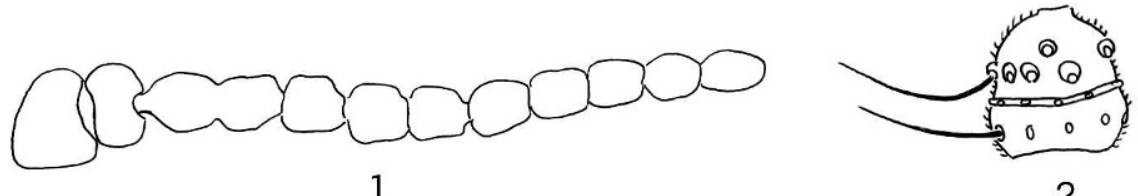

1

2
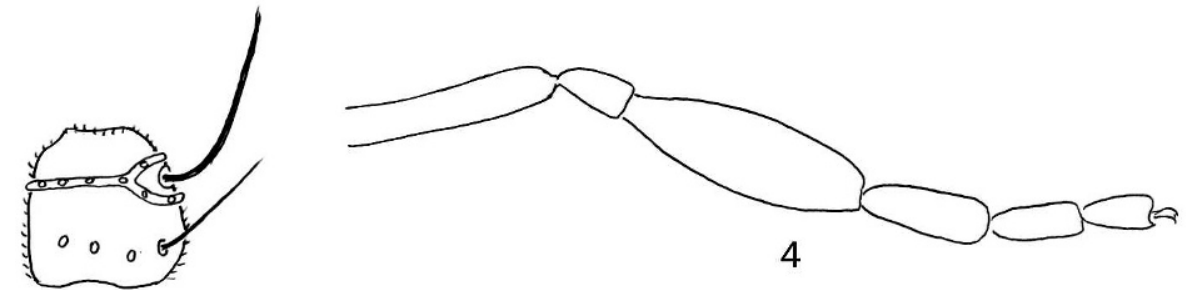

3

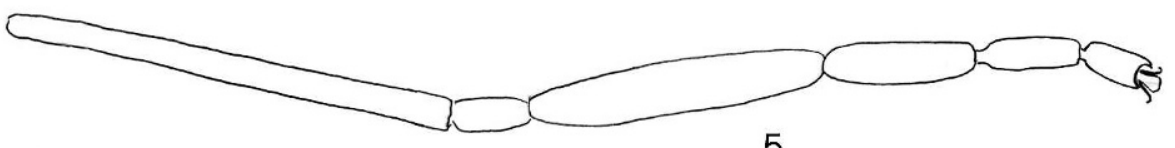

5

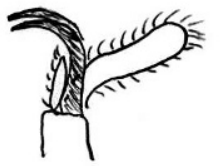

6

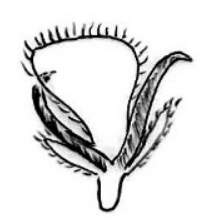

7

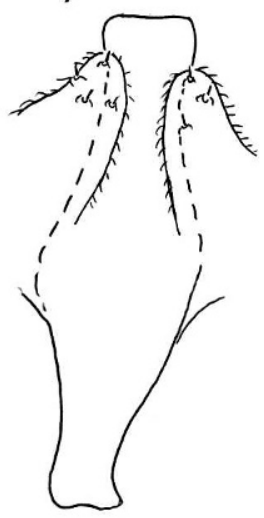

8

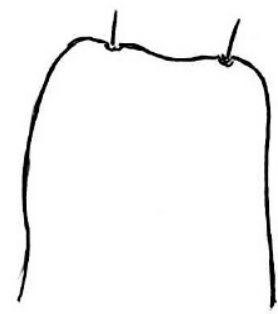

11
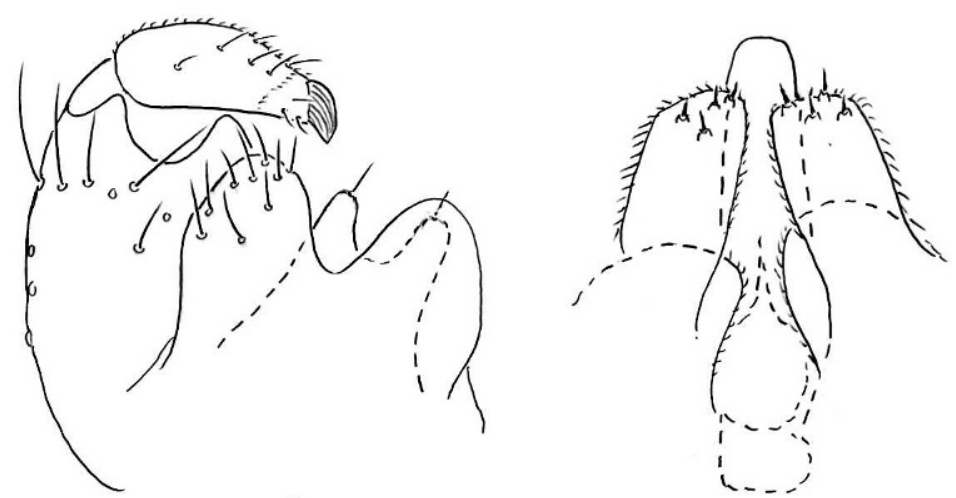

9

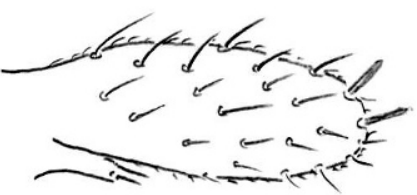

12

10

Figs. 1-12. Arnoldiola spp. 1, Male antenna, A. brevicornis. 2, Third male flagellomere, dorsal, $A$. brevicornis. 3, Third female flagellomere, ventral, A. ligni. 4, Foretarsus and part of tibia, A. caudata. 5 , Foretarsus and tibia, A. brevicornis. 6, Acropod, lateral, A. brevicornis. 7, Acropod, dorsal, A. brevicornis. 8, Male genitalia, only one gonopod shown, dorsal, A. brevicornis. 9, Aedeagus and mediobasal lobes of gonocoxites, ventral, $A$. brevicornis. 10, Aedeagus and mediobasal lobes of gonocoxites, ventral, $A$. caudata. 11, Male hypoproct, dorsal, A. caudata. 12, Female fused cerci and hypoproct, lateral, A. ligni. 
Nearctic species and specimens of at least two Palearctic species, including the type species, is the elongate, cylindrical pulvilli that reach to midlength of the tarsal claws (Figs. 6-7). An additional character in males of the Nearctic species, at least, is the broad tarsi that are noticeably wider than the femora and tibiae (Figs. 4-5). The six nominal species newly combined here with Arnoldiola differ from the Palearctic species and $A$. atra Gagné from Texas in having simple rather than toothed tarsal claws. Whether gall midge genera have toothed or simple tarsal claws is usually a good generic character, although there are exceptions where other character combinations indicate its intrageneric variation (e.g., Mayetiola Kieffer, Rabdophaga Westwood, and now Arnoldiola).

\section{Materials And Methods}

The type specimens of each of the species studied for this research are slidemounted and part of the Felt Collection, currently on long-term loan to the Systematic Entomology Laboratory from the New York State Museum in Albany. Some of the eight individual specimens lack certain body parts or are improperly displayed but are exhibited adequately to support the conclusions of this article. Terminology for adult morphology follows McAlpine et al. (1981).

\section{TAXONOMY}

The three valid species, reduced from six nominal ones, that are treated here share the following characters, many that are also shared by Dasineura and other Dasineurini: eye facets circular, contiguous on the ventral two-thirds and dorsal fourth of the eye but separated by 1 to $11 / 2$ facet diameters between those two parts and at the vertex (Gagné and Riley 1999, fig. 4); 10 cylindrical flagellomeres without necks in both sexes (Figs. 1-3); wing (Gagné and Riley 1999, fig. 11): C broken posteriad of its junction with R5; R5 attaining $\mathrm{C}$ anterior to wing apex, $\mathrm{Cu}$ forked, $\mathrm{M}$ not traceable; male tarsi appreciably wider than tibiae and femora; acropods (Figs. 6-7): tarsal claws simple, empodia enlarging from narrow base to broad apex, slightly longer than claws, pulvilli cylindrical, 1/2 length of claws; first through seventh abdominal tergites (Gagné and Riley 1999, figs. 13-14) of male and first through sixth of female with single row of sparse posterior setae, no lateral setae, scales covering at least posterior half, and a pair of anterior trichoid sensilla; male eighth tergite with anterior pair of trichoid sensilla the only vestiture; female seventh and eighth tergites (Gagné and Riley 1999, fig. 13) rectangular, subequal, much narrower than sixth, not longitudinally divided, with setae posteriorly and with anterior pair of trichoid sensilla; male genitalia (Figs. 8-11): hypoproct weakly to deeply concave apically; gonostylus short, conical, mostly setulose, parameres broad at apex, shorter than aedeagus; ovipositor (Gagné and Riley 1999, fig. 13) protrusible, elongate, the fused cerci (Fig. 12) elongate, cylindrical, setulose and setose, with two wide, blunt-tipped setae near apex; hypoproct with two distal setae.

\section{Arnoldiola azaleae (Felt), new combination}

azaleae Felt 1907a: 26 (Oligotrophus); Felt 1915: 200, redescription; Gagné 2004: 274 (unplaced Cecidomyiinae). caudata Felt 1915: 199 (Phytophaga); Gagné 2004: 275 (unplaced Cecidomyiinae). New combination, new synonym.

The holotype male of $A$. azaleae was swept from an azalea on May 18, 1906 at Albany, NY. Of the four nominal species assembled in this paper that are known from the male sex, A. caudata was the only one for which Felt (1907a, 1915) noted the swollen tarsi. The name 
azaleae is unfortunate because it implies that this species is somehow connected with azalea. Arnoldiola caudata is known from three males swept on May 9, 1910 from wild geranium, Geranium maculatum, in Albany, NY.

Arnoldiola azaleae and A. caudata are synonymized here because their genitalia are identical so far as can be determined. The genitalia of three of the four available specimens are not ideally displayed for comparison of all their parts, but visible on all four is a barely concave posterior margin of the hypoproct (Fig. 11). Unfortunately, none of the four specimens shows the mediobasal gonocoxal lobes very well. Those drawn here (Fig. 10) appear narrower than in A. brevicornis, but that could be an artifact of mounting. The conspicuously broad tarsi of this species differ from the more moderately enlarged tarsi of $A$. brevicornis (cf. Figs. 4-5). Additionally, the latter species has a deeply lobed instead of a barely concave hypoproct (cf. Figs. 8, 11).

\section{Arnoldiola brevicornis (Felt), new combination}

brevicornis Felt 1907a: 25 (Oligotrophus); Felt 1915: 219, redescription (Janetiella).

tiliacei Felt 1907a: 25 (Oligotrophus); Felt 1907b: 121, as tiliaceus, unjust. emend. of tiliacei; Felt 1915: 218, redescription (Janetiella). New combination, new synonym.

The holotype male of A. brevicornis was taken on goldenrod on June 14, 1906 in Nassau, NY. The holotype male of $A$. tiliacei was taken on basswood on May 23, 1906 in Westfield, NY. Felt did not remark upon the swollen tarsi on either nominal species.

Arnoldiola brevicornis and A. tiliacei are synonymized here because their genitalia (Figs. 8-9) are identical. This species differs from $A$. azaleae in having a moderately divided posterior margin of the hypoproct (cf. Figs. 8, 11) and less inflated tarsi (Fig. 5).

\section{Arnoldiola castaneae (Felt), new combination.}

castaneae Felt 1909: 291 (Rhopalomyia); Felt 1915: 278, redescription; Gagné 2004: 275 (unplaced Cecidomyiinae). ligni Felt 1915: 220 (Janetiella). New combination, new synonym.

The holotype female of $A$. castaneae was reared on June 13, 1908 from larvae collected at Stowe, Massachusetts the previous year from a burrlike gall (cf. Gagné 1989) on the basal part of the leaf petiole of American chestnut, Castanea dentata (Fagaceae). The holotype female of A. ligni was reared May 8, 1911 in Nassau, NY from decaying chestnut bark. The larva of this female presumably fell from leaves as it left the galls the previous year. The two specimens under this name are similar in every way, including in the shape of the fused cerci (Fig. 12). The abdomen is similar otherwise to that drawn for A. atra (Gagné and Riley 1999, fig. 13). Arnoldiola castaneae may be synonymous with either A. azaleae or A. brevicornis, but one cannot know without rearing both sexes from chestnut galls.

\section{Discussion}

The species treated here will key to couplet 182 in Gagné (1981) where one will find a choice between Janetiella Kieffer and Mayetiola. Arnoldiola differs from those genera by the foreshortened, neckless antennal flagellomeres in both sexes, the pulvilli being half the length of the tarsal claws instead of one-third or less, and the male tarsi being appreciably wider than the tibiae or femora.

Swollen tarsi or other leg parts are uncommon in Cecidomyiidae. Other than in Arnoldiola, the only other example I can think of is Trotteria Kieffer, which has greatly swollen femora as 
compared to the rest of the leg. I wondered if the pupal leg sheaths of Arnoldiola were enlarged around the tarsi, but the leg sheaths of $A$. atra are of equal width throughout, which means that while the femora and tibiae lengthen and thin out following ecdysis, the tarsi do not or do so to a relatively lesser extent. This makes sense because, were only the tarsal part of the leg sheath relatively large, the tarsi might have difficulty being drawn through the thinner part of the leg sheath during ecdysis.

Pulvilli are not always noted in descriptions of Cecidomyiidae, perhaps because they are usually not prominent, only one-third or less the length of the claws and often obscured when the claws are drawn in side view. However, they can be a useful generic character as they are here.

Empodia are often described as longer than the claws, but in many cases the claws are splayed outward (cf. Fig. 7) and only appear shorter. With six legs on a good specimen, one hopes to have some acropods that will be well enough displayed to show the relative lengths well.

\section{ACKNOWLEDGMENTS}

I am grateful to Diana Marques who finalized the plate of drawings. I thank Keith M. Harris, Woking, Surrey, United Kingdom; Allen L. Norrbom and Natalia J. Vandenberg, Systematic Entomology Laboratory; and an anony- mous reviewer for their helpful comments on the manuscript.

\section{Literature Cited}

Felt, E. P. 1907a. New Species of Cecidomyiidae. New York State Education Department, Albany. 53 pp.

1907b. Appendix: New species of Cecidomyiidae, 97-165. In Felt, E. P., ed. 22nd report of the State entomologist on injurious and other insects of the State of New York 1906. New York State Museum Bulletin 110: 39-186, 3 pls.

1909. Additional rearings in Cecidomyiidae. Journal of Economic Entomology 2: 286-293.

. 1915. Appendix: A study of gall midges II, 79-242, pls. 1-14. In Felt, E. P., ed. 30th Report of the State Entomologist on injurious and other insects of the State of New York 1913. New York State Museum Bulletin 175: $5-257,16$ pls

Gagné, R. J. 1981. Cecidomyiidae, pp. 257-292. In McAlpine, J. F., et al., eds. Manual of Nearctic Diptera. Vol. 1. Research Branch, Agriculture Canada Monograph No 27. vi + $674 \mathrm{pp}$.

. 1989. The Plant-Feeding Gall Midges of North America. Cornell University Press, Ithaca, New York. xiii \& 355 pp., 4 pls.

- 2004. A catalog of the Cecidomyiidae (Diptera) of the world. Memoirs of the Entomological Society of Washington No. 23, $408 \mathrm{pp}$.

Gagné, R. J. and E. G. Riley. 1999. A new gall midge (Diptera: Cecidomyiidae) pest of live oak in Texas. Southwestern Entomologist 24: 159-165.

McAlpine, J. F., B. V. Peterson, G. E. Shewell, H. J. Teskey, J. R. Vockeroth, and D. M. Wood, eds. 1981. Manual of Nearctic Diptera, Vol. 1. Research Branch, Agriculture Canada Monograph No 27. vi + 674 pp. 